\title{
The Assets and Challenges of Formerly Incarcerated Latino Men's Social Support Networks in Promoting Healthy Behaviors
}

\author{
Miguel Muñoz-Laboy • Omar Martinez • \\ Jeffrey Draine • Vincent Guilamo-Ramos • \\ Nicolette Severson • Ethan Levine • Gregory Benjamin
}

Published online: 4 August 2017

(C) The New York Academy of Medicine 2017
Keywords Latino men's health $\cdot$ Health promoting behaviors · Men's health $\cdot$ Latino health $\cdot$ Substance abuse prevention · Formerly incarcerated populations $\cdot$ HIV prevention · Social support

\section{Introduction}

Violence, HIV/AIDS, and alcohol and substance abuse are serious public health problems affecting formerly incarcerated Latino men (FILM) [1-5]. Imprisonment represents a major health risk. It increases incarcerated and formerly incarcerated individuals' vulnerability to STIs and trauma and exacerbates preincarceration conditions [6-8]. Non-Latino blacks and Latinos are six and three times higher, respectively, than non-Latino whites to be incarcerated; however, in the ten states with the highest concentrations of Latinos, they are five to seven times more likely to be incarcerated $[9,10]$. Moreover, Latino males currently have a higher representation among young adults US prisoners than any other ethnic groups (see Fig. 1) [11]. The reentry process into one's communities has been found to be stressful and associated with overall high risk-taking behaviors including reengaging in criminal behaviors [12-15]. Thus, in order to identify intervention strategies to enhance the social environments of FILM entering into their communities, we conducted a study to examine health-promoting attitudes, resources, and supportive interactions between FILM and their nominated social support networks.

Understanding the assets within the social environments of FILM could assist them in engaging in and 
Fig. 1 Distribution by age and ethnicity $(\%)$ of (male) prison population in the USA, as of December 31, 2013 $(n=1,412,745)$. Source of data: Carson and Anderson [11]

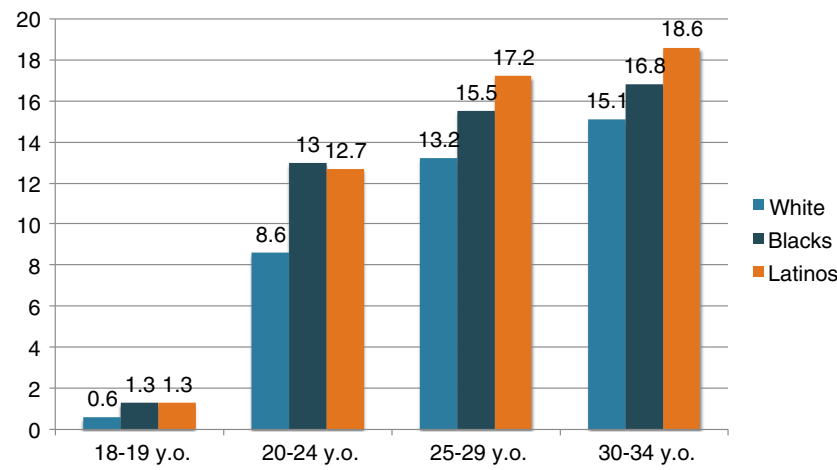

FILM nor has most research examined familia members' health-promoting practices and their capacity to support health-promoting behaviors.

The lack of attention to social support in FILM's social networks is unfortunate given the potential that these networks can provide in dealing with multiple post-incarceration stigmas and stressors and in providing multiple forms of support to these men [22]. In order to understand the social assets within the interpersonal environment post-imprisonment for FILM, we draw on the network enhancement theory (NET) and the unified theory (UT) [27-32]. NET states that the health of social networks can be improved by enhancing collective social capital, identifying strengthening factors, and increasing their efficacy while decreasing collective risk factors [27-29]. Under UT, behavior is influenced centrally by an individual's intention, skills, absence of environmental constraints, expectancies (an individual's perceived advantages and disadvantages of enacting the behavior), norms (perceived normative behavior among referents of network), and self efficacy (one's perceived confidence in performing the behavior) [16, 17, 30-32]. We designed a study based on NET construct of proximal, nominated close social support networks. From NET and UT perspectives, in order to understand FILM health-promoting and risk-taking practices, we must examine the expectancies, perceived social norms, and self-efficacy of FILM's close social networks. Thus, our analysis was guided by five hypotheses.

Higher Structural Resources Hypothesis $\left(H_{1}\right)$ Nominated social support networks will have higher socioeconomic resources such as income, mastery over English, higher acculturation, stable employment, education, and informational networks than FILM, thereby serving as an informational-financial resource to FILM. This 
hypothesis stems from two assumptions: (1) factors that lead to faster, effective mobility in the economy and labor force will increase individuals' financial and social capital allowing them to be better equip to handle stressors and health risks and engage in proactive, health-promoting practices [33, 34] and (2) similarly, higher levels of education and access to health-promoting, risk reduction information have been demonstrated to increase individuals' overall self-efficacy and healthpromoting practices $[35,36]$. Under this hypothesis, FILM would seek support from individuals within their social and kinship networks who might be at higher socioeconomic, structural positions than themselves.

The literature on social support among individuals involved in the criminal justice system suggests that sex differences in the sources of support matter in regard to the effectiveness of the type of support provided and received [37-39]. In other words, male members of men's social networks post-incarceration may provide limited effective support to individuals as these associates may be the same individuals with whom they engaged in health risk practices or criminal behaviors prior to their incarceration $[7,8,39]$. Therefore, it is important to differentiate the gender of sources of support in order to examine the potentiality of social networks in supporting FILM.

Not being currently, recently, or ever incarcerated places the nominated individual of a social support network at a higher social position (with regard to incarceration stigma and discrimination in entry into the workforce) than individuals recently released from jail or prison or those with a criminal record [40, 41]. That relative high level of social capital (in comparison to those with criminal records) could potentially enhance the networks of FILM [42]. However, this crude association does not specify the level of depth in which social capital does not necessarily support only the self but others - in this case someone coming out of jail or prison. There is no research on the depth of social capital networks on Latino communities managing the integration of formerly incarcerated individuals, which is a critical issue in urban environments like New York City.

The following hypotheses are based under the assumption that female members of FILM social networks, in urban Latino communities, have a relatively higher social capital given that the likelihood of incarceration and imprisonment is relatively low for Latina women compared to Latino men. However, the effectiveness of their providing social support needs to be examined given the sexism and violence against women that dominate American communities, including Latino urban communities [43-45].

Higher Self-Efficacy Hypothesis $\left(\mathrm{H}_{2}\right)$ Female social support networks will have higher levels of selfefficacy regarding protective health behaviors than FILM or men in FILM's close social support networks.

Higher Protective Beliefs Hypothesis $\left(H_{3}\right)$ Female social support networks will have lower positive expectancies, affective attachment towards, and agreement with norms to engage in risky behaviors compared to FILM or men in FILM's close social support networks.

Higher Effective Coping Strategies Hypothesis $\left(H_{4}\right)$ Female social support networks will have a significantly higher frequency of effective behavioral and cognitive coping strategies, lower avoidance in addressing problems and stressors, and more risky behavioral coping strategies to manage life problems than FILM or men in FILM's close social support network.

Higher Healthy Behaviors Hypothesis $\left(H_{5}\right)$ FILM will have significantly higher risk-taking behaviors than their male or female social support networks. This hypothesis is critical because, on the one hand, it is expected that through their incarceration experiences, FILM were exposed to more structural risk factors in and outside correctional facilities than their close social networks (unexposed or with limited long-term exposure to imprisonment). On the other hand, FILM may have learned life skills and other lessons from rehabilitation programs that may equip them better to handle everyday challenges in their communities, so they may behave at the same level of risk or less than their social networks.

The previous hypotheses stem from UT and NET research that suggest that self-efficacy levels, protective beliefs, and coping strategies within a social network are positively correlated [46]. The assumption guiding the previous hypotheses is that members of the support network could potentially serve as role models for healthy behaviors and risk reduction practices and will have tools that can potentially be shared with FILM to reduce the likelihood of risk-taking behaviors. To test the previous hypotheses, we conducted linear and logistic regression modeling based on data from a mixedmethod study of the intersection of sexual health risks 
and substance abuse among FILM and their nominated close social networks in New York City.

\section{Methods}

\section{Context}

This study took place in New York City which has one of the largest populations formerly incarcerated population nationwide. The New York State Department of Correctional Services (DOCS) releases approximately 25,000 people a year to the city, and the New York City jails release almost 100,000 [47, 48]. The average length of stay is 41 days for unsentenced detainees ( $70 \%$ of the jail population) and 35 days for sentenced inmates (18\% of the population) [49]. This study was conducted specifically with Latino men who had been released from prison (either from NY state or federally supervised correctional facilities) or jails (supervised by New York City county). Latinos constitute an estimated $30 \%$ of the detainee population in New York City [50]. We recruited participants from predominantly Latino neighborhoods in the city, specifically the borough of the Bronx and the neighborhoods of Washington Heights, Inwood, and East Harlem in the borough of Manhattan as most Latinos released from correctional facilities are released or returned into these neighborhoods [8]. More than half $(53.5 \%)$ of the Bronx population $(741,413$ out of $1,385,108)$ are Latino [51]. Similarly, 71.5, 72.3, and $52.1 \%$ of the population are Latino in Washington Heights, Inwood, and East Harlem, respectively [51]. These neighborhoods are historically Puerto Rican (Bronx and East Harlem), Dominican (Washington Heights and Inwood), and Mexican (Bronx and East Harlem) [51].

In the American urban context, formerly incarcerated individuals are a dynamic group, more often than not they are reincarcerated for parole violations or new criminal activity [52-54]. Sixty percent of those serving long-term sentences in state prison facilities had a prior admission registered under the NY State Department of Corrections [7, 8] Furthermore, it is estimated that 50\% of those released returned to jail within the year [7, 8] Although there are a number of programs dedicated to reintegration and reducing recidivism, we have limited knowledge how to enhance the social networks of formerly incarcerated individuals to increase their social support safety nets, promote healthy behaviors, and mitigate factors that may increase their recidivism.

\section{Design}

This analysis is based on data generated from the study Social Network Determinants of Risk among Formerly Incarcerated Latino Men (\#1RC1MH088636-01; 2009-2011). The study consisted of three data collection components: (1) formative research where 30 dyads (FILM and nominated close social network members) participated in open-ended interviews, (2) cross-sectional study consisting of a computer-administered survey with FILM, ages 18-49, who had been in jail or prison within the past 5 years $(n=259)$ and 130 dyads (FILM and nominated social network), and (3) life history interviews of trajectories of community reintegration ( $n=18$ interviewed on two occasions each). This analysis draws on the dyad data only. The detailed methodology of the study has been published elsewhere [20-22]; however, in this section, we will describe the limitations concerning the dyad data.

\section{Methodological Limitations}

We did not randomly recruit from correctional facilities as our aim was to examine FILM already relocated back into their communities. Self-selection bias and overrepresentation of certain networks are potential sampling limitations for this study [55, 56]. We minimized selfselection bias by not sharing the eligibility criteria for the study; however, our study is limited by potentially having low representation of two sectors of FILM: fulltime employed FILM with limited time to participate in the study and severely physically disabled FILM who may not have been present at the recruitment venues for the study.

The study was originally designed to recruit 200 FILM and 200 individuals that they considered their closest source of support. We recruited participants via face-to-face outreach. Interested FILM were asked to nominate a specific close member of their familia (i.e., any adult over the age of 18 who is deemed to be a significant part of the FILM's support system) for recruitment into the study. The investigative team then obtained tracking information for each of the selfidentified individuals and their nominated referent. During the recruitment process, a considerable number of FILM were unable to identify a close source of support. 
As such, we received permission to alter our inclusion criteria and allow FILM without support sources into the study. Of the 350 men that we recruited, $88.6 \%$ ( $n=310$ ) met the eligibility criteria for the study; of those, $12.9 \%$ refused to participate due to time constraints or a lack of interest and $3.5 \%$ began but did not complete the survey $(n=259)$. Of the $259,49.8 \%$ reported not having a person that they considered to be a supportive member of their family or circle of friends. Therefore, in this analysis, we will report the findings from the 130 dyads that we were able to recruit.

\section{Measures}

Background characteristics were measured in terms of demographic variables and cultural background measures that have been associated with social support systems including acculturation (SASH Brief Scale, 13 items, higher values indicate higher acculturation, $\alpha=0.91$ ) [57], familism (emotional and physical connectedness and the notion of devotion to family, scale; items 18; $\alpha=0.93$ ) [58], and religiosity (Santa Clara's Strength of Religious Faith Scale, 10 items, where a higher value indicates higher levels of religious faith, $\alpha=0.94$ ) [59]. We measured socioeconomic factors by examining the following variables: (a) education completed (years), (b) employment status at the point of the interview, (c) annual income from all sources, and (d) self-rated scale of economic position within society determined by the perceived socioeconomic status of the Add Health Survey Wave IV In-Home Interview, variable H4EC19 [60].

Cognitive proximal risk measures included expectancies, social norms, and self-efficacy. Expectanciesdyads responded to statements linking a specific behavior (unprotected sexual intercourse, marijuana use, or heavy drinking) to each of four outcomes using a fivepoint agree-disagree scale (scored 1-5). Each of the three expectancy scales had a $\alpha>.90$. Social normsdyads responded to statements on the perceived approval of their partners, close friends, family, and street family on three behaviors: unprotected sex, heavy (daily and binge) marijuana use, and heavy (daily and binge) alcohol drinking using a four-point approval scale (scored 1-4). Each of the three social norms scales had a $\alpha>0.90$. The content of the expectancies and social norms was developed based on UT methodology from the open-ended interviews during the initial qualitative phase of the study. Dyads were asked to state the advantages and disadvantages of engaging in each of the behaviors listed above at this time in their life, and their responses were content analyzed. The most frequently mentioned expectancies were used in the quantitative phase of the study. Self-efficacy was measured in three areas: (a) condom use self-efficacy (using the Marin et al. CUSE scale for unmarried Latinos, $\alpha=0.91$ ) [61]; (b) self-efficacy to stop/control alcohol use ( $\alpha=0.89$ ), and (c) self-efficacy to stop/control marijuana use $(\alpha=0.91)$. The latter two self-efficacy scales consisted of four items each measuring confidence levels under different scenarios to stop or control the behavior, ranking the level of confidence using a five-point scale for each item ( 1 = "I cannot do under any circumstance" to 5 = "Highly certain that I can"). Higher scores in these meant higher levels of selfefficacy on each specific behavior.

Sources of stress and coping strategies were measured using the Men's Coping Strategies adapted from the Brief COPE scale [62]. Participants were asked what was currently causing stress in their lives and to rank each of the options (family, work, unemployment, and health) using a six-point scale $(0=$ Not at All to $5=$ High Levels of Stress). Within each of these areas, participants were asked, after a detailed introduction, to think of the many ways that they try to deal with problems. Participants were then presented with a list of 28 items, then asked the extent to which they had been doing what the item says regardless of whether the item was working or not ( $1=$ "I haven't been doing this at all" to $4=$ "I've been doing this a lot"). Based on this information, we developed three composite measures: action-oriented positive coping strategies (mean $=2.42$, SD 0.65, $\alpha=0.83$ ), avoidance coping strategies (mean $=2.27$, SD 0.69, $\alpha=0.84$ ), and health negative coping strategies (mean $=2.26$, SD 0.70, $\alpha=0.83$ ).

Concordance in support activities refers to the level of agreement in reporting activities intended to be supportive between FILM and their support network. We listed ten supportive activities between dyads (e.g., speaking in person or by phone; accompanying person in dyad to a medical or to a social services appointment). Based on the frequencies reported by each member of the dyad in the past 30 days, we determined the level of positive concordance (both parties reported the same activity), negative concordance (both parties not reporting engaging in the same activity), and discordance (activity reported by one party but not reported by the other). 
Analytical Plan

Data were extracted from the survey database and imported into IBM SPSS Statistics version 23. Tables 1,2, and 3 present the descriptive statistics of the variables of interest. We examined our hypotheses for each of the variables conducting two main comparisons: (a) FILM versus nominated female social support (FSS) and (b) FILM versus nominated male social support (MSS). We divided the analyses by the sex of the nominated social support because data on social support systems suggest that there are differences in the type, quality, and consistency of social support provided by the gender of one's social support [63]. We used logistic regression when the dependent variable of interest was dichotomous; otherwise, we used linear regression equations. We also conducted an exploratory descriptive analysis of the sources of types of social support activities between FILM and FSS and MSS (Table 4). Additionally, we conducted a secondary descriptive analysis to supplement $\mathrm{H}_{4}$ by examining the level of concordance and discordance in participants' responses to activities that took place in the past 30 days between dyads. Our final analysis $\left(\mathrm{H}_{5}\right)$ consisted of comparing mental health indicators, sexual risk, and drug use between dyads. Prior to testing our hypotheses, we verified that our variables met the basic assumptions for linear and logistic regression modeling. For example, based on our sample size of 130 dyads, we calculated our power for each of the linear and regression models ranging between 0.82 and 0.96 . We also calculated the tolerance and variance inflation factor (VIF) values for each predictor of the logistic regression models as a check for multicollinearity [64]. The values for each of the nine models ranged between 0.15 and 0.86 (i.e., less than 0.10 is generally recommended to pursue a correctional strategy). The calculated VIF values for each of our nine models were below 10 (i.e., a variable with VIF values greater than 10 may merit further investigation) [64].

\section{Results}

Structural Resources Hypothesis $\left(H_{1}\right)$ Male and female social supports have significantly higher levels of education and familism and are more likely to be employed

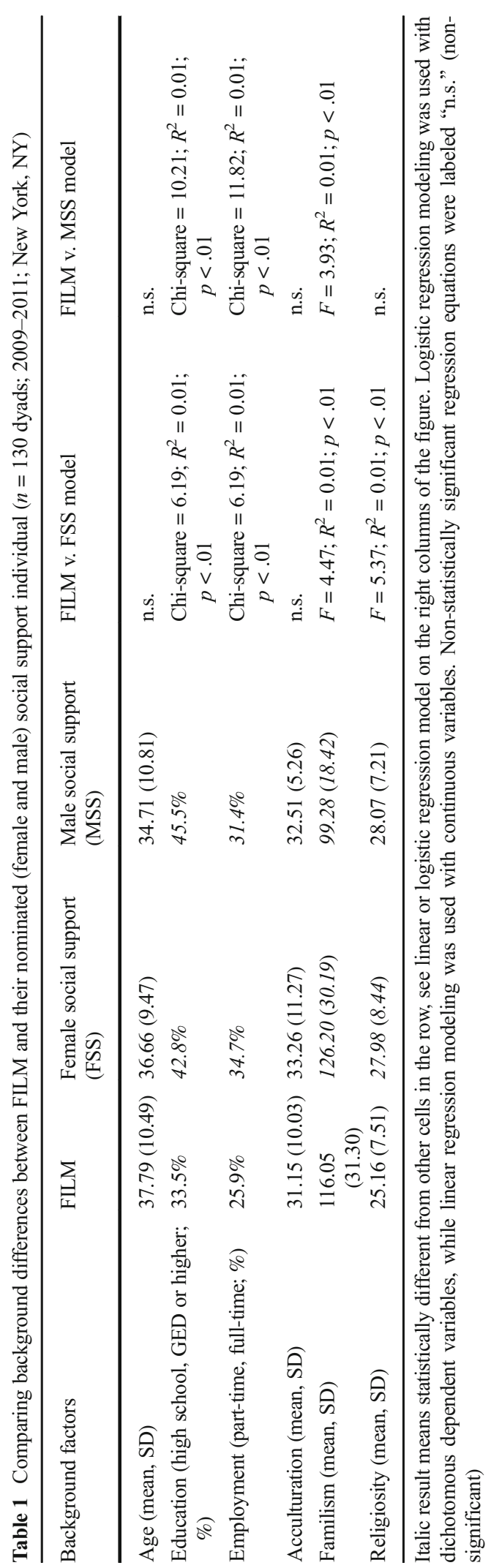


than FILM. There were no differences in terms of age and acculturation levels. However, FSS reported higher levels of religiosity than FILM (see Table 1).

Self-Efficacy Hypothesis $\left(\mathrm{H}_{2}\right)$ Female social supports reported higher self-efficacy on both indicators (condom use and stopping/controlling alcohol and marijuana use) than FILM. There were no differences in terms of selfefficacy between MSS and FILM (see Table 2).

Protective Beliefs Hypothesis $\left(H_{3}\right)$ Female social supports scored significantly higher positive expectancies towards unprotected sexual intercourse (i.e., perceived unprotected sex as normative and acceptable) and positive perceived normative approval towards risky behaviors than FILM. There were no significant differences between FILM and MSS with respect to cognitive proximal risk/protective factors (see Table 2).

\section{Coping Strategies and Social Support Hypothesis} $\left(H_{4}\right)$ There were no significant differences in types or ranking of sources of stress and coping strategies between FILM and FSS or MSS. We found overall high levels of concordance in participants' responses to dyad activities in the past 30 days with the following two being the most frequent activities between the dyads: (1) "hanging out" (spending time together) with your dyad (once a week or higher frequency) and (2) speaking in person or by phone with dyad (once a week or higher) (see Table 4).

Health Status and Health Risk Behaviors Hypothesis $\left(H_{5}\right)$ There were no significant differences between FILM and FSS or MSS in terms of indicators of major anxiety or depression, high levels of loneliness in the past 10 days, ever overdosing, sexually transmitted infections diagnosed in the past 12 months, sexual risk-taking behaviors in the past 30 days, consumption of alcohol and tobacco in the past 30 days, and lifetime use of nonprescribed use of prescription drugs. However, FILM were more likely than FSS to report moderate to daily use of marijuana and a lifetime usage of heroin (Table 5).

Table 2 Comparing proximal cognitive risk/protective factors between FILM and their nominated (female and male) social support individual ( $n=130$ dyads; 2009-2011; New York, NY)

\begin{tabular}{|c|c|c|c|c|c|}
\hline Proximal cognitive risk factors & $\begin{array}{l}\text { FILM mean } \\
(\mathrm{SD})\end{array}$ & $\begin{array}{l}\text { FSS mean } \\
(\mathrm{SD})\end{array}$ & $\begin{array}{l}\text { MSS mean } \\
(\mathrm{SD})\end{array}$ & FILM v. FSS Model & $\begin{array}{l}\text { FILM v. MSS } \\
\text { model }\end{array}$ \\
\hline Expectancies towards unprotected sex & $55.07(14.18)$ & $61.26(17.54)$ & $53.50(13.48)$ & $\begin{array}{l}F=7.36 ; R^{2}=0.02 \\
\quad p<.01\end{array}$ & n.s. \\
\hline Expectancies towards heavy drinking & $35.93(9.86)$ & $39.32(13.08)$ & $33.71(8.69)$ & n.s. & n.s. \\
\hline Expectancies towards marijuana use & $26.21(8.04)$ & $28.48(10.02)$ & $24.07(6.40)$ & n.s. & n.s. \\
\hline $\begin{array}{l}\text { Social norms (perceived approval) towards } \\
\text { unprotected sex }\end{array}$ & $30.82(9.78)$ & $36.22(10.91)$ & $30.35(9.74)$ & $\begin{array}{l}F=12.37 ; R^{2}=0.04 \\
\quad p<.001\end{array}$ & n.s. \\
\hline $\begin{array}{l}\text { Social norms (perceived approval) towards } \\
\text { heavy drinking }\end{array}$ & $14.71(4.99)$ & $19.02(5.94)$ & $13.21(3.51)$ & $\begin{array}{l}F=29.28 ; R^{2}=0.17 \\
\quad p<.001\end{array}$ & n.s. \\
\hline $\begin{array}{l}\text { Social norms (perceived approval) towards } \\
\text { marijuana use }\end{array}$ & $15.16(4.80)$ & $19.28(5.46)$ & $14.14(2.38)$ & $\begin{array}{l}F=29.44 ; R^{2}=0.09 \\
\quad p<.001\end{array}$ & n.s. \\
\hline Condom use self-efficacy & $34.30(10.17)$ & $38.22(11.28)$ & $33.43(8.12)$ & $\begin{array}{l}F=6.19 ; R^{2}=0.02 \\
p<.01\end{array}$ & n.s. \\
\hline Self-efficacy to stop/control alcohol use & $13.59(4.69)$ & $15.26(5.87)$ & $11.76(2.91)$ & $\begin{array}{l}F=4.88 ; R^{2}=0.02 \\
\quad p<.01\end{array}$ & n.s. \\
\hline Self-efficacy to stop/control marijuana use & $10.24(3.86)$ & $11.92(4.58)$ & $10.21(2.89)$ & $\begin{array}{l}F=7.51 ; R^{2}=0.02 \\
\quad p<.01\end{array}$ & n.s. \\
\hline Self-esteem & $21.79(7.39)$ & $20.26(9.06)$ & $22.21(8.74)$ & n.s. & n.s. \\
\hline Perceived stress & $16.02(6.47)$ & $15.96(7.12)$ & $16.14(6.11)$ & n.s. & n.s. \\
\hline
\end{tabular}

Italic result means statistically different from other cells in the row. Please see linear or logistic regression model on the right columns of the figure. Logistic regression modeling was used with dichotomous dependent variables, while linear regression modeling was used with continuous variables. Non-statistically significant regression equations were labeled as "n.s." Higher score means high agreement with the variable measure on the left column. High expectancy score means higher positive expectancies towards the behavior on the measure. High score in the social norm measures means high level of perceived approval from social network on engagement on the target behavior. High score in efficacy measures means high efficacy 

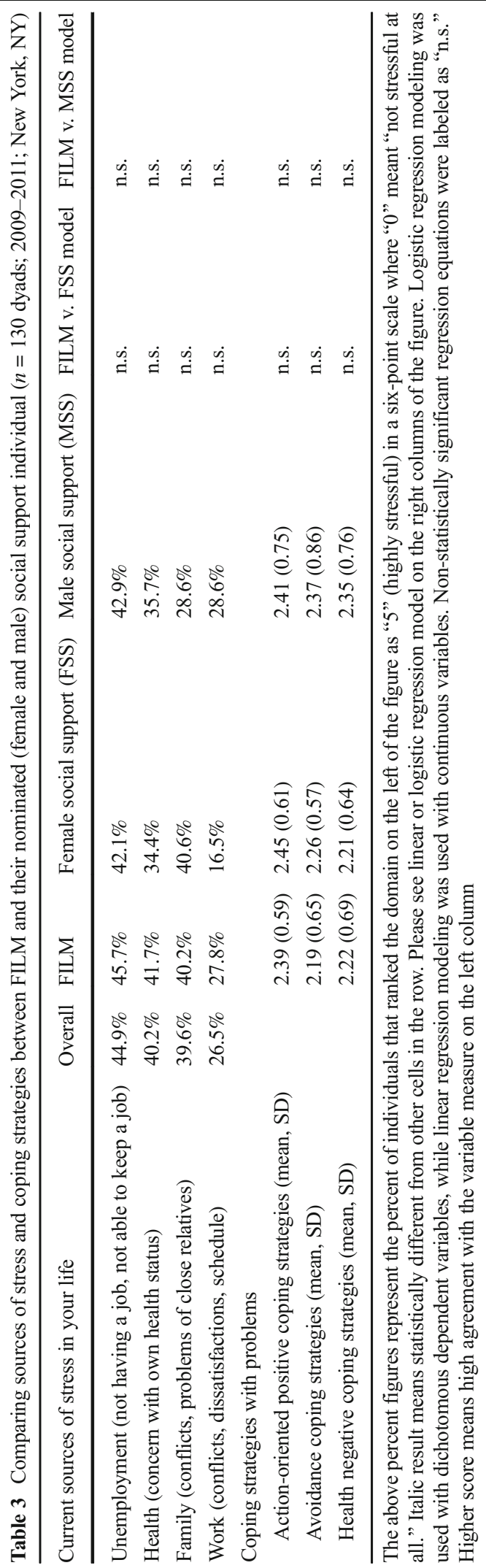

\section{Discussion}

This study was originally designed to build the foundation to develop street family and kinship family network enhancement intervention strategies. Family/kinshipbased interventions have been demonstrated to be effective in increasing health-promoting behaviors and risk reductions among Latinos and similar groups to FILM [65-70]. Our results suggest a number of limitations that need to be addressed or taken into consideration before building and implementing a family-based intervention for FILM. Our findings partially support our higher structural resources hypothesis $\left(\mathrm{H}_{1}\right)$ when nominated social support networks had higher levels of education completed and more stable employment than FILM (but no differences in other socioeconomic indicators). Not being currently, recently, or ever incarcerated placed the nominated social support networks at higher social positions (regarding incarceration stigma and discrimination in entry into the workforce) than individuals recently released from jail or prison or those who with a criminal record. Education and employment have been demonstrated to be strong predictors of health status, risk reduction, and health-promoting behaviors for Latinos and non-Latinos in the USA [71, 72]. A higher level of education has been positively associated with a higher ability to navigate health and social services [73, 74], thus making the informational support provided by MSS and FSS to FILM highly effective. Our findings reinforce the need to expand comprehensive education reform in low-income urban schools as they not only benefit the individual, but it has the potential to have a diffusion effect on the people that those individuals provide support to, in this case FILM.

Male and female social supports reported a higher commitment to family emotional connectedness and to the collective family's well-being (i.e., familism) than FILM. In the absence of internal family stigmatization, familism has been demonstrated to be a strong predictor of health-promoting practices among Latinos [75-78]. From a NET perspective, we can design strategies to reinforce familism values and practices among FILM and their kinship networks even prior to release from correctional facilities, thereby potentially minimizing the challenges of transitioning back into the community.

Our findings support our general knowledge that adult Latina women are more religious than adult Latino men [79]. However, we expected that FILM would have the same or higher level of religiosity than their social 
Table 4 Concordance in support activity reports between FILM and their nominated (female and male) social support individual $(n=130$ dyads; 2009-2011; New York, NY)

\begin{tabular}{|c|c|c|c|}
\hline Support activities between FILM and support person & $\begin{array}{l}\text { Concordant positive } \\
\text { responses }(\%)\end{array}$ & $\begin{array}{l}\text { Concordant negative } \\
\text { responses }(\%)\end{array}$ & $\begin{array}{l}\text { Discordant } \\
\text { responses }(\%)\end{array}$ \\
\hline Hanging out with your friend/relative (once a week or higher) & 78.1 & 16.7 & 5.3 \\
\hline $\begin{array}{l}\text { Speaking in person or by phone with your friend/relative who is also } \\
\text { completing the survey (once a week or higher) }\end{array}$ & 72.1 & 19.2 & 8.7 \\
\hline $\begin{array}{l}\text { Provided transportation to your friend/relative to a medical or to a social } \\
\text { services appointment }\end{array}$ & 45.1 & 54.9 & 0 \\
\hline Bought or helped doing groceries or cooking for your friend/relative & 44.4 & 55.6 & 0 \\
\hline $\begin{array}{l}\text { Accompanied your friend/relative to a medical or to a social services } \\
\text { appointment }\end{array}$ & 42.9 & 57.1 & 0 \\
\hline Helped your friend in translating forms and assisting in filling out forms & 41.7 & 58.3 & 0 \\
\hline Prayed for your friend/relative for his well-being & 40.9 & 55.6 & 3.5 \\
\hline $\begin{array}{l}\text { Helped your friend/relative in taking care of his children or family } \\
\text { members }\end{array}$ & 37.6 & 62.4 & 0 \\
\hline Gave your friend/relative advice, guidance or mentoring & 36.8 & 45.5 & 17.6 \\
\hline Listening to your friend/relative's problems (once a week or higher) & 31.6 & 18.2 & 50.2 \\
\hline
\end{tabular}

Concordant positive responses refer to both FILM and nominated social support individual reporting independently the occurrence of the activity on the left within the past 30 days. Concordant negative responses refer to both FILM and nominated social support individual reporting independently the activity on the left that did not took place within the past 30 days. Discordant responses mean level of incongruence between FILM and nominated support individual on whether the activity took place or not

supports given how important religious affiliation becomes during incarceration [80]. Furthermore, developing health promotion initiatives for FILM and their familias using progressive religious institutions in lowincome Latino communities might be an effective venue. For example, Muñoz-Laboy and Perry [81] documented the use of a local Episcopalian parish in a highcrime, low-income neighborhood to facilitate support groups for FILM including the blessing of condoms at the altar by a Latina priest [19].

Moving from the structural-cultural assets of social supports, $\mathrm{H}_{2}-\mathrm{H}_{4}$ focused on the capabilities of social network members to support health-promoting and risk reduction behaviors. Here is where we observed major differences between the genders of the social support individual. Male social supports were not different from FILM regarding self-efficacy, protective beliefs, and coping strategies. This suggests that MSS might have the same values and beliefs regarding risk taking, in this case, sexual risk taking and binge substance use and abuse, as FILM; therefore, rather than serving as sources of support for health-promoting practices, they may unintentionally reinforcement risk-taking attitudes. However, as our indicators of risk-taking are genderized practices among Latinos (e.g., sex and substance use), it is unknown whether this would be the case if our indicators focused on less genderized behaviors such as sedentary behavior.

Female social supports were similar to FILM regarding protective beliefs and coping strategies, potentially reflecting their network values of risk. However, FSS reported higher levels of self-efficacy regarding condom use and substance use. This offers a potential point of entry for health-promoting messaging, i.e., emulating being able to be efficacious with sexual risk taking and substance use, in spite of dominant risk-taking social network values.

Finally, our findings did not support our healthy behaviors hypothesis $\left(\mathrm{H}_{5}\right)$; i.e., there were no differences between FILM and MSS or FSS regarding mental health and risk-taking behaviors. Members of the social networks of FILM overall behave at the same risk levels as FILM themselves, and reported the same levels of loneliness, anxiety, and depression. This suggests that, as do the findings from $\mathrm{H}_{2}-\mathrm{H}_{4}$, a point of common logic, close social support networks reflect the same attitudes and practices as FILM. From social networks research and the principle of homophily, we know that individuals choose friends who are similar to them and that individuals feel close to family members who reflect their own worldviews and practices [82, 83]. If we intend to design health-promoting family-based 
Table 5 Comparing mental health indicators, sexual risk, and drug usage between FILM and their nominated social support individual

\begin{tabular}{|c|c|c|c|c|c|c|}
\hline \multirow[t]{2}{*}{ Group } & \multicolumn{3}{|c|}{ Anxiety } & \multicolumn{2}{|l|}{ Depression } & \multirow{2}{*}{$\begin{array}{l}\text { Loneliness } \\
\text { OR }(95 \% \mathrm{CI})\end{array}$} \\
\hline & $\%$ & OR $(95 \% \mathrm{CI})$ & $\%$ & OR $(95 \% \mathrm{CI})$ & $\%$ & \\
\hline FILM & 30.5 & 1.00 & 26.3 & 1.00 & 35.5 & 1.00 \\
\hline FSS & 28.3 & $0.89(.48,1.65)$ & 30.1 & $0.80(0.43,1.49)$ & 26.1 & $1.02(0.54,1.91)$ \\
\hline \multirow[t]{3}{*}{ MSS } & 28.6 & $1.08(0.37,3.21)$ & 14.3 & $0.73(0.24,2.24)$ & 21.4 & $0.49(0.14,1.82)$ \\
\hline & & Ever OD & & STI (12 months) & & Sexual risk exposure (30 days) \\
\hline & $\%$ & OR $(95 \% \mathrm{CI})$ & $\%$ & OR $(95 \% \mathrm{CI})$ & $\%$ & OR $(95 \% \mathrm{CI})$ \\
\hline FILM & 12.7 & 1.00 & 35.1 & 1.00 & 31.7 & 1.00 \\
\hline FSS & 8.3 & $0.84(0.41,1.73)$ & 18.2 & $0.41(0.16,1.06)$ & 20.4 & $0.54(0.26,1.13)$ \\
\hline \multirow[t]{4}{*}{ MSS } & 14.3 & $0.43(0.13,1.49)$ & 21.4 & $0.34(0.09,1.25)$ & 14.3 & $0.36(0.08,1.64)$ \\
\hline & \multicolumn{6}{|c|}{ Past 30 days moderate to daily use } \\
\hline & & Alcohol & \multicolumn{3}{|c|}{ Tobacco cigarette } & Marijuana \\
\hline & $\%$ & OR $(95 \% \mathrm{CI})$ & $\%$ & OR $(95 \% \mathrm{CI})$ & $\%$ & OR $(95 \% \mathrm{CI})$ \\
\hline FILM & 60.2 & 1.00 & 59.1 & 1.00 & 58.3 & 1.00 \\
\hline FSS & 54.1 & $0.78(0.42,1.43)$ & 46.5 & $0.59(0.32,1.09)$ & 38.1 & $0.44(0.24,0.82)$ \\
\hline \multirow[t]{4}{*}{ MSS } & 52.1 & $0.88(0.29,2.61)$ & 42.9 & $0.52(0.18,1.54)$ & 50.6 & $0.71(0.24,2.09)$ \\
\hline & \multicolumn{6}{|c|}{ Most frequent non-prescribed use of prescription drugs (lifetime) } \\
\hline & & Pain killers & & Sedatives & & Stimulants \\
\hline & $\%$ & OR $(95 \% \mathrm{CI})$ & $\%$ & OR $(95 \% \mathrm{CI})$ & $\%$ & OR $(95 \% \mathrm{CI})$ \\
\hline FILM & 27.4 & 1.00 & 21.6 & 1.00 & 16.2 & 1.00 \\
\hline FSS & 18.7 & $0.58(0.27,1.26)$ & 12.1 & $0.49(0.21,1.22)$ & 8.1 & $0.45(0.15,1.32)$ \\
\hline \multirow[t]{4}{*}{ MSS } & 21.4 & $0.72(0.11,2.66)$ & 21.4 & $0.99(0.27,3.66)$ & 21.4 & $1.41(0.38,5.27)$ \\
\hline & \multicolumn{6}{|c|}{ Most frequent schedule 1 drugs (lifetime) } \\
\hline & & Powder cocaine & & Crack cocaine & & Ecstasy \\
\hline & $\%$ & OR $(95 \% \mathrm{CI})$ & $\%$ & OR $(95 \% \mathrm{CI})$ & $\%$ & OR $(95 \% \mathrm{CI})$ \\
\hline FILM & 30.9 & 1.00 & 30.9 & 1.00 & 20.8 & 1.00 \\
\hline FSS & 18.3 & $0.49(0.33,1.06)$ & 18.3 & $0.69(0.31,1.56)$ & 18.1 & $0.83(0.38,1.82)$ \\
\hline \multirow[t]{3}{*}{ MSS } & 21.4 & $0.61(0.17,2.25)$ & 21.4 & $0.99(0.27,3.67)$ & 14.3 & $0.63(0.14,2.92)$ \\
\hline & & PCP & & Ketamine & & Heroin \\
\hline & $\%$ & OR (95\% CI) & $\%$ & OR (95\% CI) & $\%$ & OR $(95 \% \mathrm{CI})$ \\
\hline FILM & 20.8 & 1.00 & 13.1 & 1.00 & 12.7 & 1.00 \\
\hline FSS & 18.1 & $0.92(0.38,2.19)$ & 8.3 & $0.58(0.19,1.71)$ & 8.3 & $0.43(0.19,0.74)$ \\
\hline MSS & 14.3 & $0.43(0.05,3.41)$ & 14.3 & $1.10(0.24,5.14)$ & 14.2 & $0.37(0.08,1.71)$ \\
\hline
\end{tabular}

Formerly incarcerated Latino men, FILM, $n=130$; nominated female social support individual, FSS, $n=101$; nominated male social support individual, MSS, $n=29 ; 2009-2011$; New York, NY. Italic odds ratios (OR) with an asterisk indicate statistical significance at the 0.05 level. STI refers to sexually transmitted infection

initiatives targeting FILM, we must also target FILM's familias as behavioral-attitudinal peers, not just as traditional family members with higher behavioral resources than the target population, with messages and tools that promote positive behavioral changes and the maintenance of supportive environments [84]. For example, we must encourage familia members to promote healthy behaviors such as not binge drinking which would familia members to reduce their own binge drinking.

Finally, our findings suggest three additional intervention targets for FILM from a family perspective. First, binge marijuana smoking was higher among FILM than among FSS, suggesting a behavior outside of the female familial network. Second, FSS reported an overall minimal history of heroin use, thereby 
potentially serving as sources of support for FILM struggling with heroin and opioid dependence. We did not detect a difference in history of heroin use between FILM and MSS; however, we did not have information on MSS current dependence on heroin and/or opioids. Former heroin/opioid addicts can serve as sponsors to FILM who may restart opioid use post-release as a way of coping with the reentry process or relapse due to physical dependence. This is particularly important given the rise of the nationwide opioid epidemic from black tar heroin, brown powder heroin, oxycodone, and other pills [85-89]. Finally, in this study, we recruited 130 dyads; however, there were 70 FILM who did not participate in this dyad analysis as they were unable to identify one person that they considered a friend or source of support. This highlights a central problem among FILM: high levels of loneliness and social isolation in spite of membership into street families (gangs) [22].

In spite of the previous limitations, the social support provided to FILM by their social networks had a positive impact in reducing the likelihood of STIs and depression and increasing the utilization of health and social services, as documented in a prior analysis with 259 FILM [22]. This was also supported by the high levels of concurrency of the social support activities between FILM and FSS or MSS. The findings from the previous dyads suggest that familias could serve as core service delivery strategy in health promotion for FILM provided a careful incorporation of the insights from this analysis in providing us with the specificities needed to enhance the social support networks of FILM.

Acknowledgements Data for this analysis was generated from the study sponsored by the U.S. National Institute of Mental Health:Network Determinants of Sexual Risk, Alcohol and Marijuana Binge Use among Formerly Incarcerated LatinoMen (grant \#1RC1MH088636-01). This study was approved by Columbia University (CU IRB protocol \#AAAE4697) and Temple University (TU IRB protocol \#20641) Institutional Review Boards. Additionally, aCertificate of Confidentiality was obtained from the National Institute of Mental Health in order to protect theprivacy and confidentiality of the study participants. We would like to thank our research participants and themembers of our research team: Santos Bobet, Ilka Bobet, Erica Paik, Ashley Perry, Hector Ramos, FranciscoQuiñones and Samuel Santiago. The content of this article is solely the responsibility of the authors and doesnot necessarily represent the official views of the U.S. National Institute of Mental Health or the National Institutes of Health.

\section{References}

1. Sanders-Phillips K. The ecology of urban violence: its relationship to health promotion behaviors in low-income black and Latino communities. AJHP. 1996;10(4):308-17.

2. Campsmith ML, Rhodes PH, Hall HI, Green TA. Undiagnosed HIV prevalence among adults and adolescents in the United States at the end of 2006. JAIDS. 2010;53(5):619-24.

3. Freudenberg N. Jails, prisons, and the health of urban populations: a review of the impact of the correctional system on community health. J Urban Health. 2001;78(2):214-35.

4. Herbst JH, Kay LS, Passin WF, Lyles CM, Crepaz N, Marín BV, et al., HIV/AIDS Prevention Research Synthesis (PRS) Team. A systematic review and meta-analysis of behavioral interventions to reduce HIV risk behaviors of Hispanics in the United States and Puerto Rico. AIDS \& Behavior. 2007;11(1):25-47.

5. Martinez R. Latino homicide: immigration, violence, and community. New York, NY: Routledge; 2014

6. Binswanger IA, Stern MF, Deyo RA, Heagerty PJ, Cheadle A, Elmore JG, et al. Release from prison - a high risk of death for former inmates. NEJM. 2007;356(2):157-65.

7. Freudenberg N, Daniels J, Crum M, Perkins T, Richie BE. Coming home from jail: the social and health consequences of community reentry for women, male adolescents, and their families and communities. AJPH. 2005;95(10):1725-36.

8. Van Olphen J, Freudenberg N, Fortin P, Galea S. Community reentry: perceptions of people with substance use problems returning home from New York City jails. $J$ Urban Health. 2006;83(3):372-81.

9. Velasquez RJ, Funes SM. The mass incarceration of Latinos in the United States: looking ahead to the year 2050. Color Behind Bars: Racism in the US Prison System: Racism in the US Prison System, 273. 2014.

10. Morín JL. Latino/as and US prisons. In Behind Bars Palgrave Macmillan US. 2009:17-38.

11. Carson EA, Anderson E. Prisoners in 2015. Washington, DC: Bureau of justice statistics. Available online at: https://www.bjs.gov/content/pub/pdf/p15.pdf. 2015. Accessed 10 Feb 2016.

12. Listwan SJ, Cullen FT, Latessa EJ. How to prevent prisoners re-entry programs from failing: insights from evidencebased corrections. Fed Probat. 2006;70:19.

13. Wallace D, Fahmy C, Cotton L, Jimmons C, McKay R, Stoffer S, et al. Examining the role of familial support during prison and after release on post-incarceration mental health. Int J Offender Therapy Comp Criminol. 2016;60(1):3-20.

14. Western B, Braga AA, Davis J, Sirois C. Stress and hardship after prison. A J Soc. 2015;120(5):1512-47.

15. Draine J, Wolff N, Jacoby JE, Hartwell S, Duclos C. Understanding community re-entry of former prisoners with mental illness: a conceptual model to guide new research. Beh Sci Law. 2005;23(5):689-707.

16. Bandura A. Social Foundations of Thought and Action: a Social Cognitive Theory. Upper Saddle River: Prentice-Hall Inc.; 1986.

17. Rosenstock IM, Strecher VJ, Becker MH. Social learning theory and the health belief model. Health Educ Beh. 1988;15(2):175-83. 
18. Morrow KM. The Project START Study Group 1. HIV, STD, and hepatitis risk behaviors of young men before and after incarceration. AIDS Care. 2009;21(2):235-43.

19. Muñoz-Laboy M, Perry A, Bobet I, et al. The "knucklehead" approach and what matters in terms of health for formerly incarcerated Latino men. SSM. 2012;74(11):1765-73.

20. Muñoz-Laboy M, Garcia J, Perry A, Guilamo-Ramos V, Severson N. Social network factors associated with sexually transmitted infections among formerly incarcerated Latino men. Int J Sexual Health. 2013;25(2):163-8.

21. Muñoz-Laboy M, Severson N, Perry A, Guilamo-Ramos V. Differential impact of types of social support in the mental health of formerly incarcerated Latino men. Am J Mens Health. 2014;8(3):226-39.

22. Muñoz-Laboy M, Worthington N, Perry A, et al. Socioenvironmental risks for untreated depression among formerly incarcerated Latino men. J Immigr Minor Health. 2014;16(6):1183-92.

23. Miller HV, Barnes JC, Hartley RD. Reconsidering Hispanic gang membership and acculturation in a multivariate context. Crime \& Delinquency. 2011;57(3):331-55.

24. Turjeman H, Mesch G, Fishman G. Social identity, identity formation, and delinquency. Int J Comp Soc. 2008;49(2-3): 111-26.

25. McCarthy B, Hagan J, Martin MJ. In and out of harm's way: violent victimization and the social capital of fictive street families. Criminology. 2002;40(4):831-66.

26. Smith H. Searching for kinship the creation of street families among homeless youth. Am Beh Scientist. 2008;51(6):756-71.

27. Heaney CA, Israel BA. Social networks and social support. Health Behav Health Educ Theory Res Pract. 2008;4:189-210.

28. Israel BA. Social networks and health status: linking theory, research, and practice. Pat Couns Health Educ. 1982;4(2): 65-79.

29. Berkman LF, Glass T. Social integration, social networks, social support, and health. Soc Epi. 2000;1:137-73.

30. Greenwald AG, Banaji M, Rudnam L, Farnham S, Nosek BA, Mellott D. A unified theory of implicit attitudes, stereotypes, self-esteem, and self-concept. Psych Rev. 2002;109:3-25.

31. Guilamo-Ramos V, Jaccard J, Dittus P, Collins S. Parentadolescent communication about sexual intercourse: an analysis of maternal reluctance to communicate. Health Psych. 2008;27(6):760.

32. McKay MM, Pinto RM, Bannon WM Jr, Guilamo-Ramos V. Understanding motivators and challenges to involving urban parents as collaborators in HIV prevention research efforts. Social Work Mental Health. 2007;5(1-2):169-85.

33. Kawachi I, Kennedy BP, Glass R. Social capital and selfrated health: a contextual analysis. Am J Public Health. 1999;89(8):1187-93.

34. Veenstra G. Social capital, SES and health: an individuallevel analysis. Soc Sci Med. 2000;50(5):619-29.

35. Ross, C. E., \& Wu, C. L. (1995). The links between education and health. American sociological review, 719-745.

36. Cutler, D. M., \& Lleras-Muney, A. (2006). Education and Health: Evaluating Theories and Evidence (No. w12352). National Bureau of Economic Research. New York, NY

37. Mills A, Codd H. Prisoners' families and offender management: mobilizing social capital. Probat J. 2008;55(1):9-24.
38. Pinquart M, Sörensen S. Gender differences in caregiver stressors, social resources, and health: an updated meta-analysis. J Gerontol Ser B Psychol Sci Soc Sci. 2006;61(1):P33-45.

39. Fox AD, Anderson MR, Bartlett G, Valverde J, Starrels JL, Cunningham CO. Health outcomes and retention in care following release from prison for patients of an urban postincarceration transitions clinic. $J$ Health Care Poor Underserved. 2014;25(3):1139.

40. Pager D, Bonikowski B, Western B. Discrimination in a lowwage labor market: a field experiment. Am Sociol Rev. 2009;74(5):777-99.

41. Western B, Pettit B. Incarceration \& social inequality. Daedalus. 2010;139(3):8-19.

42. Pager D. The mark of a criminal record 1. Am J Sociol. 2003;108(5):937-75.

43. Torres JB, Solberg VSH, Carlstrom AH. The myth of sameness among Latino men and their machismo. Am J Orthopsychiatry. 2002;72(2):163.

44. Vidales GT. Arrested justice: the multifaceted plight of immigrant Latinas who faced domestic violence. $J$ Fam Violence. 2010;25(6):533-44.

45. Ellison CG, Trinitapoli JA, Anderson KL, Johnson BR. Race/ethnicity, religious involvement, and domestic violence. Violence Against Women. 2007;13(11):1094-112.

46. Smith KP, Christakis NA. Social networks and health. Annu Rev Sociol. 2008;34:405-29.

47. Drucker E. A Plague of Prisons: the Epidemiology of Mass Incarceration in America. New York: The New Press; 2013.

48. Santora, M. (2013). City's annual cost per inmate is $\$ 168$, 000, study finds. New York Times, August 23, 2013, p. A16.

49. New York City Dept of Correction (2016). Annual Report, 2015. New York, NY: City of New York. Available at: https://www.google.com/url? sa=t\&rct=j\&q=\&esrc= $\mathrm{s} \& \mathrm{~s}$ o u r c e $=$ w e b $\& \mathrm{~cd}=4 \& \mathrm{v}$ e $\mathrm{d}=0$ a h U K Ew i p 8 MGQouPTAhXPZiYKHWHmA-AQFgg0MAM\&url= http $\% 3 \mathrm{~A} \% 2 \mathrm{~F} \% 2$ Fwww.nycja.org $\% 2$ Flwdems $\% 2$ Fdoc-view. php\%3Fmodule\%3Dreports\%26module_id\%3D1577\%26 doc_name\%3Ddoc\&usg=AFQjCNHwp3lzdxzRLcbAjH4 ahPjuTEzrLQ Accessed on: March 15, 2017.

50. Mauer M, King RS. Uneven Justice: State Rates of Incarceration by Race and Ethnicity (pp. 1-23). Washington, DC: Sentencing Project; 2007.

51. US Census (2017). New York City, New York-tables. Available at: https:// ww w. census. gov/quickfacts/table/RHI105210/3651000 Accessed on: March 15, 2017.

52. Lim S, Seligson AL, Parvez FM, Luther CW, Mavinkurve MP, Binswanger IA, et al. Risks of drug-related death, suicide, and homicide during the immediate post-release period among people released from New York City jails, 2001-2005. Am J Epidemiol. 2012;175(6):519-26.

53. Harrison LD. The revolving prison door for drug-involved offenders: challenges and opportunities. Crime Delinquency. 2001;47(3):462-85.

54. Anestis JC, Carbonell JL. Stopping the revolving door: effectiveness of mental health court in reducing recidivism by mentally ill offenders. Psychiatr Serv. 2014;65(9):1105-12.

55. Heckman J. Varieties of selection bias. Am Econ Rev. 1990;80(2):313-8.

56. Fan X, Thompson B, Wang L. Effects of sample size, estimation methods, and model specification on structural 
equation modeling fit indexes. Struc Equation Modeling. 1999;6(1):56-83.

57. Barona A, Miller JA. Short acculturation scale for Hispanic youth (SASH-Y): a preliminary report. Hisp J Behav Sci. 1994;16(2):155-62.

58. Steidel AGL, Contreras JM. A new familism scale for use with Latino populations. Hisp J Behav Sci. 2003;25(3):31230.

59. Plante TG, Vallaeys CL, Sherman AC, Wallston KA. The development of a brief version of the Santa Clara Strength of Religious Faith Questionnaire. Pastoral Psych. 2002;50(5): 359-68.

60. UNC Carolina Population Center. Add Health survey instrument, Survey Wave IV In-Home Interview, variable H4EC19. SES self-rated ladder scale. Accessed on September 15, 2009 at http://www.cpc.unc. edu/projects/addhealth

61. Marin BV, Tschann JM, Gómez CA, Gregorich S. Selfefficacy to use condoms in unmarried Latino adults. AJCP. 1998;26(1):53-71.

62. Carver CS. You want to measure coping but your protocol's too long: consider the brief COPE. Int J Behav Med. 1997;4(1):92-100.

63. Mulvaney-Day NE, Alegria M, Sribney W. Social cohesion, social support, and health among Latinos in the United States. SSM. 2007;64(2):477-95.

64. Powers DA, Xie Y, Xie Y. Statistical Methods for Categorical Data Analysis. New York: Academic Press; 2000.

65. Kitzmann KM, Beech BM. Family-based interventions for pediatric obesity: methodological and conceptual challenges from family psychology. J Fam Psychol. 2006;20(2):17589.

66. Weisz JR, Sandler IN, Durlak JA, Anton BS. Promoting and protecting youth mental health through evidence-based prevention and treatment. Am Psych. 2005;60(6):628.

67. Kumpfer KL, Alvarado R, Smith P, Bellamy N. Cultural sensitivity and adaptation in family-based prevention interventions. Prev Sc. 2002;3(3):241-6.

68. Santisteban DA, Mena MP. Culturally informed and flexible family-based treatment for adolescents: a tailored and integrative treatment for Hispanic youth. Fam Process. 2009;48(2):253-68.

69. Guilamo-Ramos V, Bouris A, Jaccard J, Gonzalez B, McCoy W, Aranda D. A parent-based intervention to reduce sexual risk behavior in early adolescence: building alliances between physicians, social workers, and parents. J Adoles Health. 2011;48(2):159-63.

70. Bouris A, Guilamo-Ramos V, Pickard A, et al. A systematic review of parental influences on the health and well-being of lesbian, gay, and bisexual youth: time for a new public health research and practice agenda. J Primary Prev. 2010;31(5-6): 273-309.

71. Marmot M. Social determinants of health inequalities. Lancet. 2005;365(9464):1099-104.

72. Noguera P, Hurtado A, Fergus E. Invisible no more: understanding the disenfranchisement of Latino men and boys. New York, NY: Routledge; 2013
73. Kickbusch IS. Health literacy: addressing the health and education divide. Health Promo Int. 2001;16(3):289-97.

74. Sentell T, Braun KL. Low health literacy, limited English proficiency, and health status in Asians, Latinos, and other racial/ethnic groups in California. J Health Comm. 2012; 17(sup3): 82-99.

75. Perez K, Cruess D. The impact of familism on physical and mental health among Hispanics in the United States. Health Psych Rev. 2014;8(1):95-127.

76. Campos B, Ullman JB, Aguilera A, Dunkel-Schetter C. Familism and psychological health: the intervening role of closeness and social support. Cult Diver Eth Min Psych. 2014;20(2):191.

77. Savage B, Foli KJ, Edwards NE, Abrahamson K. Familism and health care provision to Hispanic older adults. J Geront Nurs. 2015;42(1):21-9.

78. De Santis JP, Provencio-Vasquez E, Mancera B, Mata HJ. Health risk and protective factors among Hispanic women living in the US-Mexico border region. Hisp Health Care Inter. 2016;14(1):17-25.

79. Peña M, Frehill LM. Latina religious practice: analyzing cultural dimensions in measures of religiosity. J Scient Study Religion. 1998:620-35.

80. Maruna S, Wilson L, Curran K. Why God is often found behind bars: prison conversions and the crisis of self-narrative. Res Human Develop. 2006;3(2-3):161-84.

81. Muñoz-Laboy M, Perry A. Reducing sexual and reproductive health disparities among Latino Men: Exploring solutions in the boundaries of masculinity. In: Nogueras P, Hurtado A, Fergus E, editors. Invisible no more: understanding the disenfranchisement of Latino boys and men. London and New York: Routledge; p. 57-78.

82. McPherson M, Smith-Lovin L, Cook JM. Birds of a feather: homophily in social networks. Ann Rev Soc. 2001:415-44.

83. Borgatti SP, Mehra A, Brass DJ, Labianca G. Network analysis in the social sciences. Science. 2009;323(5916): 892-5.

84. Lee JJ, Guilamo-Ramos V, Muñoz-Laboy M, Lotz K, Bornheimer L. Mechanisms of familial influence on reentry among formerly incarcerated Latino men. Soc Work. 2016;61(3):199-207.

85. Maxwell JC. The prescription drug epidemic in the United States: a perfect storm. Drug Alcoh Rev. 2011;30(3):264-70.

86. Springer SA, Chen S, Altice FL. Improved HIV and substance abuse treatment outcomes for released HIV-infected prisoners: the impact of buprenorphine treatment. J Urban Health. 2010;87(4):592-602.

87. Wilkerson RG, Kim HK, Windsor TA, Mareiniss DP. The opioid epidemic in the United States. Emer Medicine Clinics of North America. 2016;34(2):e1-e23.

88. Dart RC, Surratt HL, Cicero TJ, et al. Trends in opioid analgesic abuse and mortality in the United States. NEJM. 2005;372(3):241-8.

89. Visconti AJ, Santos GM, Lemos NP, Burke C, Coffin PO. Opioid overdose deaths in the city and county of San Francisco: prevalence, distribution, and disparities. $J$ Urban Health. 2015;92(4):758-72. 